\title{
REMOVAL OF PHTHALIC ACID AND ISOPHTHALIC ACID FROM AQUEOUS SOLUTION BY ANION EXCHANGE RESIN
}

\author{
MERVE DURAN, ÖZGÜR ARAR* AND MÜŞERREF ARDA
}

Ege University Faculty of Science, Department of Chemistry, Izmir 35040, Turkey Ege University Faculty of Science, Department of Chemistry, Izmir 35040, Turkey Faculty of Science, Department of Chemistry, Ege University, Izmir 35040, Turkey

\begin{abstract}
This study investigated the efficiency of a strongly basic anion exchange resin for the removal of phthalic acid (also known as orto-phthalic acid) and isophthalic acid in aqueous solutions. Uptake behavior of resin towards phthalic acid and isophthalic acid has been assessed as a function of resin dose, initial solution $\mathrm{pH}$, and temperature. The pseudo-second-order rate equation fitted well kinetic profiles for such sorbates. Phthalic acid and isophthalic acid loading isotherm studies have been performed and experimental data were analyzed by Freundlich, Langmuir and Dubinin-Radusckevich (D-R) equations. The maximum sorption capacity of the resin predicted by the Langmuir model were $397.8 \mathrm{mg} \mathrm{g}^{-1}$ for the phthalic acid and $331.3 \mathrm{mg} \mathrm{g}$ for isophthalic acid. The mean free sorption energies through the D-R model suggest that sorption takes place mainly through an ion exchange mechanism. The experimental results illustrated that the sorption of phthalic acid onto anion exchange resin is feasible, spontaneous and exothermic however, sorption of isophthalic acid is endothermic. The successful phthalic acid-loaded resin regeneration in a batch system revealed the higher efficiency of the $2.0 \mathrm{M} \mathrm{HCl}$ solution compared to $1.0 \mathrm{M} \mathrm{HCl}$ and $1.0 \mathrm{M} \mathrm{NaOH}$ as desorbing agents. In the case of isophthalic acid-loaded resin, $2.0 \mathrm{M} \mathrm{NaCl}$ solution found to be most efficient regenerant.
\end{abstract}

Keywords: Finex AS510GC, Ion exchange, Isophthalic acid, Phthalic acid, Regeneration

\section{INTRODUCTION}

Phthalates are the dialkyl or alkyl aryl ester derivatives of 1,2-benzenedicarboxylic acid [1]. They are mostly used as plasticizers to improve the flexibility and durability of polyvinyl chloride (PVC)-based plastics and less significant phthalate applications include components of inks, adhesive materials, lacquers, sealing and packing materials, as well as additives in other kinds of cosmetics [2]. Phthalates are not chemically bound to plastics thus it is suspected that a major part of the phthalates in the environment come from phthalate-containing products [3] and the adsorption performance of dimethyl phthalate (DMP). Phthalates may migrate from a plastic item to the medium, which they are in contact. Various factors such as the properties of the polymer, amount of the plasticizer, plasticization process, as well as temperature and contact area may affect their migration [4].

As a kind of endocrine disrupting chemical, phthalic acid esters (PAEs) show estrogen effects and a variety of biological toxicity. Investigations have shown that PAEs can reduce fertility and pregnancy rates in humans and animal models and can increase miscarriages and other gestational complications. Some PAEs and their metabolites produce reproductive and developmental toxicities in laboratory animals $[5,6]$. The toxicological evaluation of these chemicals has shown that low molecular weight phthalates, such as diethyl phthalate (DEP), can cause irritation of eye, nose, and throat. However, several larger phthalate molecules, such as Bis(2-ethylhexyl) phthalate (DEHP), Benzyl butyl phthalate (BBP), Diisononyl Phthalate (DINP) and Diisodecyl phthalate (DIDP), are suspected as human cancer-causing agents, could damage liver and kidneys, might damage the development of reproductive organs, and might interfere with development by acting as a mimic of the sex hormone estrogen [7]. The PAEs became one of the important pollutants in wastewater and increased awareness of phthalate ester toxicity increased the concern about the fate and removal of such pollutants in and from the environment [8]. The properties, toxic effect and removal methods of the PAEs is reviewed by various authors $[1,2,8]$

Phthalic acid is the main degradation product of phthalic acid anhydride and various phthalate esters and exists as a neutral acid or negatively charged anions, hydrogen phthalate $\left(\mathrm{H}-\mathrm{PA}^{-}\right)$and phthalate $\left(\mathrm{PA}^{2-}\right)$ in solution depending on the $\mathrm{pH}$ since the $\mathrm{p} K_{\mathrm{a}}$ values of $\mathrm{H}_{2}-\mathrm{PA}$ are 2.9 and 5.4 [9].

The main objective of this study was to remove phthalic acid (also known as orto-phthalic acid, OPA) and isophthalic acid (IPA) in aqueous solution by using the strongly basic anion exchange resin. Effects of various factors on OPA and IPA removal, such as resin dosage, initial solution $\mathrm{pH}$, and reaction temperature were systematically investigated. Subsequently, the kinetics of uptake were studied to understand the resin uptake process and to analyze the rate-controlling step. In addition, the desorption performance of resin was evaluated.

\section{EXPERIMENTAL}

2.1 Chemicals

The isophthalic acid (Acros Organics), the phthalic acid anhydride (BDH), $\mathrm{NaOH}$ (Merck) and $\mathrm{HCl}$ (VWR) and was purchased and was used as received. All solutions were prepared in pure water. IPA solution was prepared by dissolving appropriate amounts in water (with adding a sufficient amount of 2.0 $\mathrm{M} \mathrm{NaOH}$ solution). OPA solution was prepared by dissolving the proper amount of phthalic acid anhydride in water with heating. The $\mathrm{pH}$ of the solution was adjusted with $2.0 \mathrm{M} \mathrm{NaOH}$ or $\mathrm{HCl}$ solution.

\subsection{Instruments}

The analysis of analytes was performed spectrophotometrically by double beam spectrophotometer (T80+ model PG Instruments, England) at $280 \mathrm{~nm}$ for OPA and $277 \mathrm{~nm}$ for IPA. The $\mathrm{pH}$ of solutions measured with using FG2 model pH meter (Mettler Toledo, Switzerland). Nüve (Turkey) ST402 model shaking water bath used in batch sorption tests. Wisebath WB-11 model (Korea) water bath and Biosan (Latvia) multi-mixer were used in kinetic experiments.

2.3 Ion exchange resin and its preparation

Finex AS510GC (Finex, Finland), a strongly basic anion exchange resin (OH-form) was used for all experiments. Resins were initially converted to $\mathrm{OH}$ form treating $2.0 \mathrm{M} \mathrm{NaOH}$ solution with a resin-to- $\mathrm{NaOH}$ solution ratio of 1.0 $\mathrm{mL} / 1.0 \mathrm{~mL}$ and then rinsed with pure water until the $\mathrm{pH}$ of the effluent solution reached 9 or lower. After washing, resins were dried in an oven and then used in the experiments. The physical properties and specifications of resin reported by the supplier are shown in Table 1 .

Table 1: Characteristics of Finex AS510GC anion exchange resin

\begin{tabular}{|c|c|}
\hline Matrix & Styrene-divinylbenzene copolymer, Gel type \\
\hline Functional group & Quarternary amine \\
\hline Cross-linkage & $5 \%$ with DVB \\
\hline Mean bead size & $300 \pm 20 \mu \mathrm{m}$ \\
\hline Volume capacity & Min. $1.0 \mathrm{eq} / 1\left(\mathrm{OH}^{-}\right)$ \\
\hline
\end{tabular}

2.4 Batch sorption experiments

In order to optimize the sorption parameters for removal of OPA and IPA, different parameters were tested. In this batch tests, $25.0 \mathrm{~mL}$ of OPA $(50.0$ $\mathrm{mg} / \mathrm{L}, \mathrm{pH} 4)$ or IPA $(50.0 \mathrm{mg} / \mathrm{L}, \mathrm{pH} 10)$ was used. Experimental conditions for such parameters were summarized in Table 2. All experimental parameters were tested twice (except kinetic experiment) and the mean of results was presented. Each sample analyzed three times and the standard deviation of measuremen is lower than $1 \%$. The difference between the parallel experiments is lower than $3 \%$. 
The percent removal (R\%) of OPA/IPA was calculated with Eqn. 1 and capacity of sorbent (q as mg-/g-sorbent) was calculated with Eqn.2.

$$
\begin{aligned}
& R(\%)=\frac{C_{0}-C_{e}}{C_{0}} \times 100 \\
& q=\frac{\left(C_{0}-C_{e}\right) x V}{m}
\end{aligned}
$$

In these equations, $\mathrm{C}_{0}$ is the initial concentration of OPA/IPA $(\mathrm{mg} / \mathrm{L}), \mathrm{C}_{\mathrm{e}}$ is the concentration of IPA/OPA in the solution after sorption experiment (mg/L). V is the volume of solution (L) and $\mathrm{m}$ is the mass of the resin $(\mathrm{g})$.

Table 2: Experimental parameters for sorption experiments.

\begin{tabular}{|c|c|c|c|c|}
\hline $\begin{array}{c}\text { Investigated } \\
\text { parameter }\end{array}$ & $\begin{array}{c}\text { phthalic acid / isophthalic acid } \\
\text { concentration (mg/L) }\end{array}$ & $\begin{array}{c}\text { Amount of } \\
\text { sorbent }(\mathbf{g})\end{array}$ & $\begin{array}{c}\text { Volume of } \\
\text { solution (mL) }\end{array}$ & pH of solution \\
\hline Sorbent dose & 50.0 & from 0.01 to 0.04 & 25.0 & $4(\mathrm{OPA}) 10$ (IPA) \\
\hline Initial solution pH & 50.0 & 0.02 & 25.0 & 25 \\
\hline Equilibrium study & from 100 to 800 & 0.02 & 25.0 & $4(\mathrm{OPA}) 10(\mathrm{IPA})$ \\
\hline Temperature effect & 50.0 & 0.02 & 25.0 & 4 (OPA) 10 (IPA) \\
\hline Kinetic study & 50.0 & 0.80 & 1000.0 & 40,40 and 50 (OPA) 10 (IPA) \\
\hline
\end{tabular}

\section{RESULTS AND DISCUSSION}

3.1 Effect of resin dosage on OPA and IPA removal

The removal of OPA and IPA by ion exchange resin at different resin dosages is illustrated in Figure 1, respectively. For both OPA and IPA, the removal efficiency increased with an increase in the ion exchange resin dose, resulting from the major number of active sites provided for the uptake [10].

It was found out that the optimum resin dosage was $0.02 \mathrm{~g}$ resin/ $25.0 \mathrm{~mL}$ for OPA and IPA removal and such resin dose was used in subsequent batch parameters.

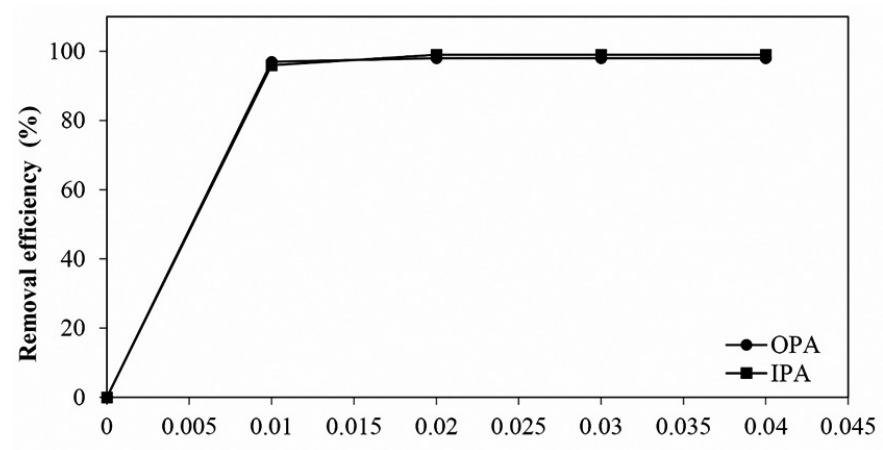

Resin dose (g-resin / $25 \mathrm{~mL}$ of solution)

Figure 1: Removal of OPA and IPA as a function of resin dose.

3.2 Effect of initial solution $\mathrm{pH}$ on OPA and IPA removal

The properties of both sorbent and solute may be influenced by the solution $\mathrm{pH}$, especially when the adsorbate has weak acidic or basic property. The effect of solution $\mathrm{pH}$ for the sorption of OPA and IPA onto ion exchange resin was studied in the $\mathrm{pH}$ range 1-5 and obtained results depicted in Figure 2.

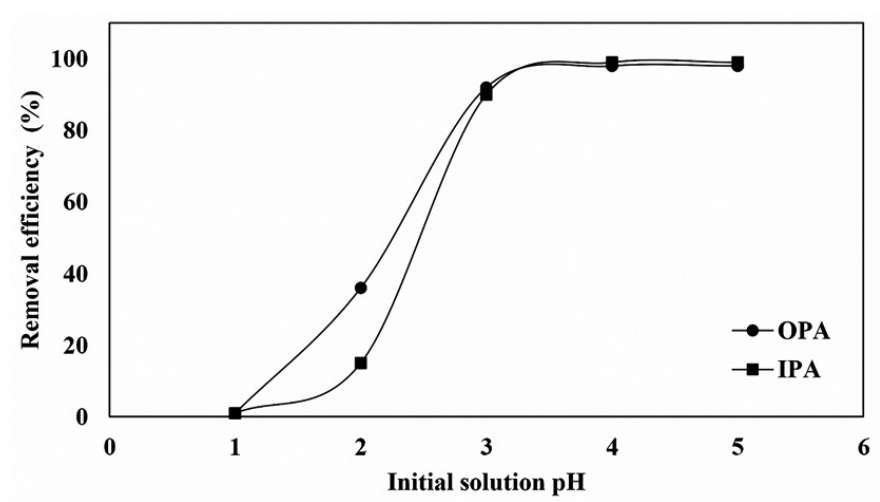

Figure 2: Effect of solution $\mathrm{pH}$ on OPA and IPA removal.

It is clear from the figure that, at $\mathrm{pH} 1$, removal of such acid is about $1 \%$ and when the $\mathrm{pH}$ of the solution was increased, enhancement on the removal rate observed. This can be explained as follows. Both of OPA and IPA weak di-acid and their acid ionization constants are $\mathrm{pK}_{\mathrm{a} 1} 2.95, \mathrm{pK}_{\mathrm{a} 2} 5.91$ for OPA; $\mathrm{pK}_{31} 3.62, \mathrm{pK}_{2} 4.60$ for IPA[11]. The chemical structures and speciation of such acids are shown in Figures 3-5.

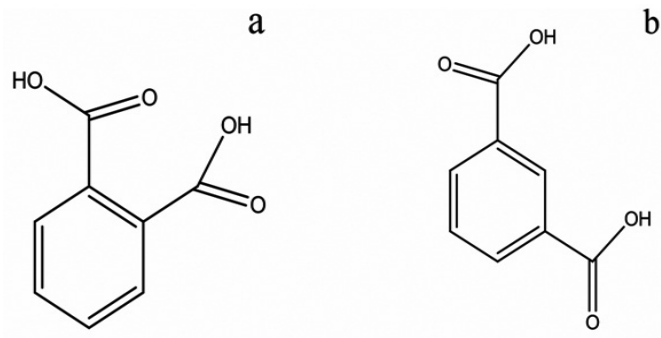

Figure 3: Chemical structure of phthalic acid (a) and isophthalic acid (b). 


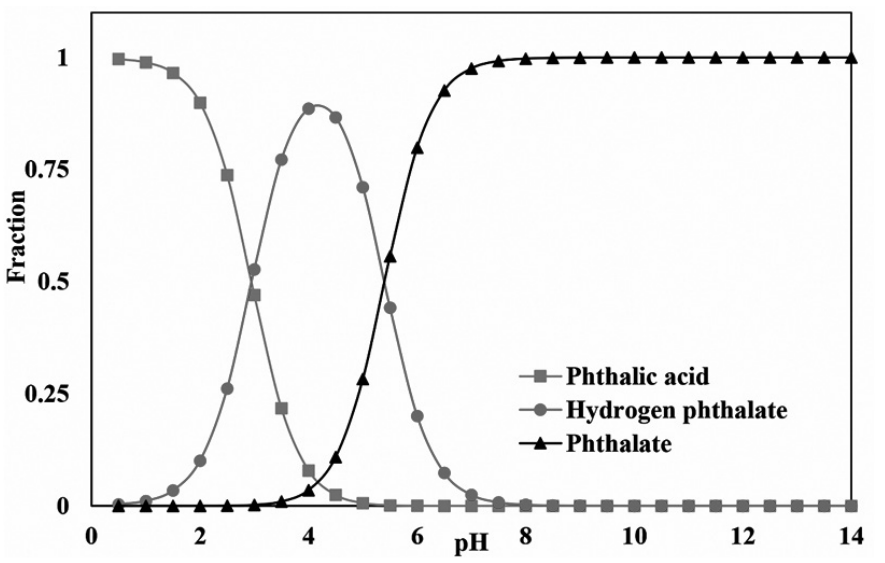

Figure 4: $\mathrm{pH}$ versus speciation plot for phthalic acid.

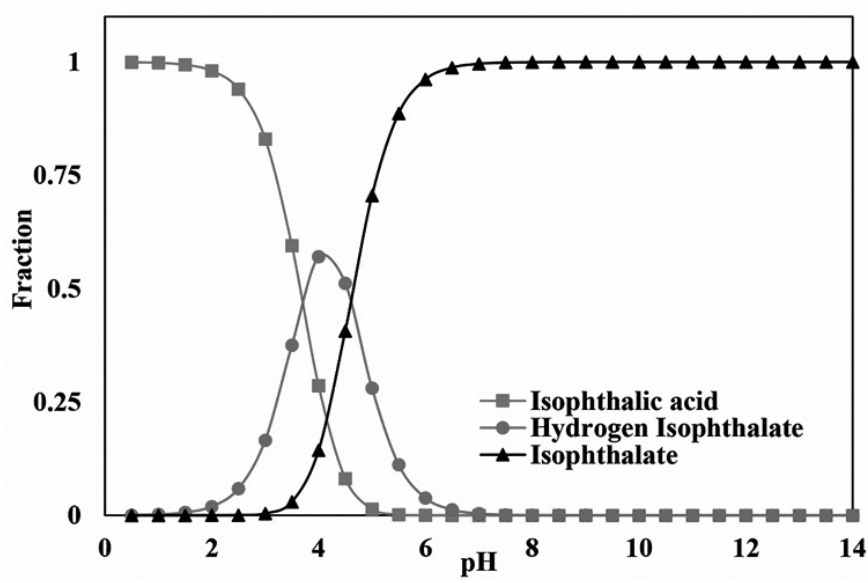

Figure 5: $\mathrm{pH}$ versus speciation plot for isophthalic acid.

When the $\mathrm{pH}$ of the solution was adjusted to $\mathrm{pH} \mathrm{1,} \mathrm{OPA} \mathrm{and} \mathrm{IPA} \mathrm{turned}$ to their molecular form and did not involve the ion exchange reaction [12]. Low removal rate (about $1 \%$ ) may be as molecular sorption onto the resin. The elevation of solution $\mathrm{pH}$ leads to increment on OPA and IPA ionic fraction and such ionic forms involved ion-exchange reaction with resin thus percent removal of sorbates increased [13].

3.3 Sorption isotherms

The relationship between the initial OPA or IPA concentration and the amount of sorbed acids onto ion exchange resin is shown in Figure 6. The data indicate that the uptake capacity increases with enhancing initial concentration in the solution and then the uptake capacity reaches a plateau, which indicates that OPA or IPA has occupied most active binding sites on the resin.

In order to obtain the theoretical sorption capacity, experimental results were fitted to the two most common isotherm models, i.e., the Langmuir and Freundlich models. The Langmuir equation is valid for monolayer sorption onto a surface is given as follows $[14,15]$.

$$
\frac{C_{e}}{Q_{e}}=\frac{1}{b Q_{0}}+\frac{C_{e}}{Q_{0}}
$$

$\mathrm{Ce}$ is equilibrium concentration $(\mathrm{mg} / \mathrm{L})$, Qe is the amount sorbed ion under equilibrium (mg/g), $\mathrm{Q}_{0}$ is the theoretical maximum sorption capacity, and b (L/ $\mathrm{mg}$ ) is a Langmuir constant, which indicates the affinity of the OPA or IPA toward the resin.

The Freundlich equation, indicative of surface heterogeneity of the adsorbent, is given as follows

$$
\log Q_{e}=\log K_{F}+\frac{1}{n} \log C_{e}
$$

$1 / \mathrm{n}$ and $\mathrm{K}_{\mathrm{F}}$ are Freundlich constants, related to sorption capacity and sorption intensity (heterogeneity factor), respectively, Qe is the amount of OPA/IPA sorbed per unit weight of the resin (mg/g-resin), and Ce is the equilibrium concentration of sorbate in solution $(\mathrm{mg} / \mathrm{L})$. The obtained and calculated parameters were summarized in Table 3 .

According to the results presented in Table 3, the sorption of IPA and OPA onto ion exchange resin is more of monolayer sorption rather than sorption on a surface having heterogeneous energy distribution.

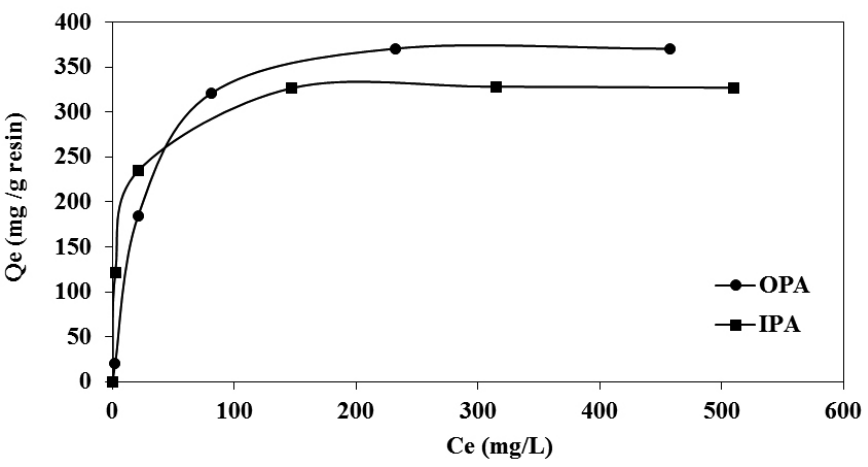

Figure 6: Sorption isotherm of OPA and IPA onto AS510GC resin.

Table 3: Isotherm constants for OPA and IPA sorption on the resin

\begin{tabular}{|c|c|c|c|c|c|c|}
\hline \multirow{2}{*}{ Analyte } & \multicolumn{3}{|c|}{ Langmuir Isotherm Constants } & \multicolumn{3}{c|}{$\begin{array}{c}\text { Freundlich Isotherm } \\
\text { Constants }\end{array}$} \\
\cline { 2 - 7 } & $\mathrm{Q}_{0}\left(\mathrm{mg} \cdot \mathrm{g}^{-1}\right)$ & $\mathrm{b}(\mathrm{L} / \mathrm{mg})$ & $\mathrm{R}^{2}$ & $\begin{array}{c}\mathrm{K}_{\mathrm{F}} \\
(\mathrm{mg} / \mathrm{g})\end{array}$ & $\mathrm{n}$ & $\mathrm{R}^{2}$ \\
\hline OPA & 397.8 & 0.04 & 0.9970 & 20.1 & 1.8 & 0.8665 \\
\hline IPA & 331.3 & 0.20 & 0.9998 & 115.2 & 5.4 & 0.9201 \\
\hline
\end{tabular}

The maximum adsorption capacity $\left(\mathrm{Q}_{0}\right)$ of resin for the OPA is higher than for IPA. Such difference could be a steric effect (because of different molecular shape) and hydrated radius.

\subsection{Dubinin-Radushkevich (D-R) model}

The Dubinin-Radushkevich model is another model, which was used for the clarification of the mechanism of sorption (i.e., physical or chemical). The linear D-R equation is given in Eq. 5 where $\beta$ is the constant related to sorption energy $\left(\mathrm{mol}^{2} \mathrm{~J}^{-2}\right), \mathrm{X}\left(\mathrm{mol} \mathrm{g}^{-1}\right)$ is the Dubinin-Radushkevich monolayer capacity, $\mathrm{q}_{\mathrm{e}}\left(\mathrm{mol} \mathrm{g}^{-1}\right)$ is the amount of sorbed OPA or IPA per unit weight of resin, $\varepsilon\left(\mathrm{mol} \mathrm{L}^{-1}\right)$ is the Polanyi potential that is calculated as shown in Eq. 6 . In these equations, $\mathrm{Ce}$ is the equilibrium concentration of sorbate, $\mathrm{R}$ gas constant $\left(8.314 \mathrm{~J} \mathrm{~mol}^{-1} \mathrm{~K}^{-1}\right)$ and $\mathrm{T}$ the temperature $(\mathrm{K})$. The mean free energy $\mathrm{E}\left(\mathrm{kJ} \mathrm{mol}^{-}\right.$ $\left.{ }^{1}\right)$ of sorption can be estimated by using $\beta$ values as expressed in the following Eqn. $5-7[16,17]$

$$
\begin{aligned}
& \ln Q_{e}=\ln X_{m}-\beta \varepsilon^{2} \\
& \varepsilon=R T \ln \left(1+\frac{1}{C_{e}}\right) \\
& E=\frac{1}{\sqrt{2 \beta}}
\end{aligned}
$$

For values of $\mathrm{E}<8 \mathrm{~kJ} \mathrm{~mol}^{-1}$, physical forces may have an effect on the sorption mechanism while $\mathrm{E}$ values between 8 and $16 \mathrm{~kJ} \mathrm{~mol}^{-1}$ depict the sorption is controlled by ion exchange and $\mathrm{E}>16 \mathrm{~kJ} \mathrm{~mol}^{-1}$ signifies the process is chemisorption [18]. In our case, mean free energy E value was 9 for OPA and 15 for IPA, which indicates that the removal mechanism is ion exchange. The ion-exchange reaction of resin with phthalate isomers (denoted as $\mathrm{C}_{8} \mathrm{H}_{4} \mathrm{O}_{4}^{2-}$ ) can be expressed in Eq. 8 


$$
\overline{2(\mathrm{R}-\mathrm{OH})}+\mathrm{C}_{8} \mathrm{H}_{4} \mathrm{O}_{4}^{2-} \leftrightarrow \overline{(\mathrm{R})_{2} \mathrm{C}_{8} \mathrm{H}_{4} \mathrm{O}_{4}}+2 \mathrm{OH}^{-}
$$

\subsection{Sorption kinetics}

The sorption capacity of AS510GC resin for OPA and IPA versus time is presented in Figure 7. It can be discerned that the sorption process increased sharply at the beginning of contact time. Following that, the increment slowed down and finally approached equilibrium.

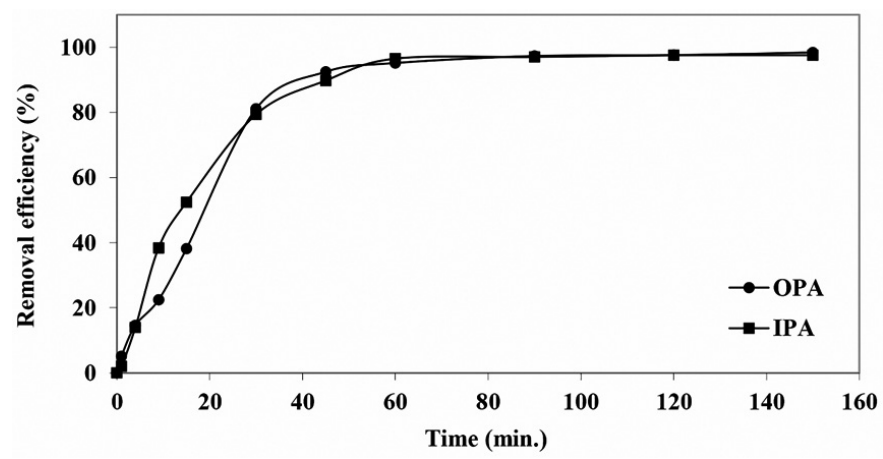

Figure 7: Removal of OPA and IPA versus time.

The experimental data in Fig. 7 were analyzed using the following pseudofirst-order (Eq.9), and pseudo-second-order (Eq. 10) kinetic models [19,20].

$$
\begin{aligned}
& \log \left(Q_{e}-Q_{t}\right)=\log \left(Q_{e}\right)-\frac{k_{1} t}{2.303} \\
& \frac{t}{Q_{t}}=\frac{1}{k_{2} Q_{e}^{2}}+\frac{1}{Q_{e}} t
\end{aligned}
$$

The calculated parameters of pseudo-first and second-order kinetic models were summarized in Table 4. The pseudo-first-order kinetic model was found to provide the best fit to the kinetic data for the obtained results.

Table 4: The calculated parameters of kinetic models.

\begin{tabular}{|c|c|c|c|}
\hline Kinetic model & Parameter & OPA & IPA \\
\hline \multirow{3}{*}{ Pseudo First order } & $\mathrm{k}_{1}\left(\mathrm{~min}^{-1}\right)$ & 0.07 & 0.08 \\
\cline { 2 - 4 } & $\mathrm{q}_{\mathrm{e}}(\mathrm{mg} / \mathrm{g})$ & 77.43 & 72.2 \\
\cline { 2 - 4 } & $\mathrm{R}^{2}$ & 0.9938 & 0.9853 \\
\hline \multirow{3}{*}{ Pseudo Second order } & $\mathrm{k}_{2}(\mathrm{~g} / \mathrm{mg} \min )$ & 0.0065 & 0.0002 \\
\cline { 2 - 4 } & $\mathrm{q}_{\mathrm{e}}(\mathrm{mg} / \mathrm{g})$ & 90.5 & 105.9 \\
\cline { 2 - 4 } & $\mathrm{R}^{2}$ & 0.9192 & 0.1798 \\
\hline
\end{tabular}

The OPA and IPA sorption kinetic data are used for homogeneous particle diffusion model (HPDM) and shell-progressive model (SPM). According to the homogeneous particle diffusion model, if the solid (in our case, ion exchange resin) contains enough porosity to allow the fluid reactant to pass through freely, it is reasonable to assume that the reaction between solid and fluid occurs uniformly throughout the solid phase. Thus, solid reactant is converted continuously and progressively. In the case of the shell-progressive model, the porosity of the solid polymer is small, either because of its internal structure or due to its swelling properties. The polymer is thus practically impervious to the fluid reactant, and the initial reaction is to be visualized as taking place on the outer surface of the solid bead. The site of the reaction then moves inwards, the reaction itself occurring continuously at the surface of the unreacted core $[21,22]$. The related equations and $R^{2}$ values are given in Table 5 .

\begin{tabular}{|c|c|c|c|c|c|}
\hline \multirow{2}{*}{ Method } & \multirow{2}{*}{ Equation } & \multirow{2}{*}{$\mathbf{k}$} & \multirow{2}{*}{$\begin{array}{c}\text { Rate- } \\
\text { controlling } \\
\text { step }\end{array}$} & \multicolumn{2}{|c|}{$\mathbf{R}^{2}$ value } \\
\hline & & & & OPA & IPA \\
\hline \multirow{2}{*}{ HPDM } & $\stackrel{-\mathrm{ln}}{(1-X)=\mathrm{k}_{\mathrm{li}} \mathrm{t}}$ & $\begin{array}{c}\mathrm{k}=3 \mathrm{DC} / \\
\mathrm{r}_{\mathrm{o}} \delta \mathrm{Cr}\end{array}$ & Film diffusion & 0.9846 & 0.9992 \\
\hline & $\begin{array}{l}-\ln \left(1-X^{2}\right) \\
=k t,\end{array}$ & $\mathrm{k}=\operatorname{Dr} \pi^{2} / \mathrm{r}_{\mathrm{o}}^{2}$ & $\begin{array}{l}\text { Particle } \\
\text { diffusion }\end{array}$ & 0.9731 & 0.9824 \\
\hline \multirow{3}{*}{$S P M$} & $\mathbf{x}$ & $\begin{array}{c}\mathrm{k}=3 \mathrm{C}_{\mathrm{Ao}} \mathrm{K}_{\mathrm{MA}} / \\
\operatorname{ar}_{\mathrm{o}} \mathrm{C}_{\mathrm{So}}\end{array}$ & Liquid film & 0.9132 & 0.9087 \\
\hline & $\begin{array}{l}3-3(1-X)^{2 /} \\
{ }^{3}-2 X=k t\end{array}$ & $\begin{array}{c}\mathrm{k}=6 \mathrm{D}_{\mathrm{eR}} \mathrm{C}_{\mathrm{Ao}}{ }^{\prime} \\
\mathrm{ar}_{\mathrm{o}}{ }^{2} \mathrm{C}_{\mathrm{So}}\end{array}$ & Reacted layer & 0.9661 & 0.9902 \\
\hline & $\begin{array}{c}1-(1-X)^{1 / 3} \\
=k t\end{array}$ & $\mathrm{k}=\mathrm{K}_{\mathrm{s}} \mathrm{C}_{\mathrm{Ao}} / \mathrm{r}_{\mathrm{o}}$ & $\begin{array}{l}\text { Chemical } \\
\text { reaction }\end{array}$ & 0.9715 & 0.9879 \\
\hline
\end{tabular}

Table 5: Linear regression analysis data related to kinetic models on sorption kinetics of OPA and IPA

The linear correlations coefficients for HPDM model indicated that film diffusion was the rate-limiting step for both ions. According to the SPM model, chemical reaction was the rate-limiting step for OPA sorption and reacted layer was for IPA sorption.

\subsection{Thermodynamic parameters}

The effect of the solution temperature on the removal of OPA and IPA from water was examined by changing the solution temperature from 30 to $50^{\circ} \mathrm{C}$ under the optimized conditions resin dose and solution $\mathrm{pH}$. Changes in standard free energy $\left(\Delta \mathrm{G}^{\circ}\right)$, entropy $\left(\Delta \mathrm{S}^{\circ}\right)$ and enthalpy $\left(\Delta \mathrm{H}^{\circ}\right)$ were estimated by the following Eq. $11-13[23,24]$.

$$
\Delta G^{0}=-\mathrm{RT} \ln K_{c}^{0}
$$

$$
\ln K_{c}^{0}=\frac{\Delta \mathrm{S}^{0}}{\mathrm{R}}-\frac{\Delta \mathrm{H}^{0}}{\mathrm{RT}}
$$

$$
\Delta G^{\circ}=\Delta H^{\circ}-T \Delta S^{\circ}
$$

In these equations, $\mathrm{K}$ is the equilibrium constant and it was calculated by $\mathrm{q}_{\mathrm{e}} / \mathrm{C}, \mathrm{R}$ is the universal gas constant $\left(8.314 \mathrm{~J} \mathrm{~mol}^{-1} \mathrm{~K}^{-1}\right)$, and $\mathrm{T}$ is the temperature $(\mathrm{K})$. Parameters change in enthalpy $\left(\Delta \mathrm{H}^{0}\right)$ and change in entropy $\left(\Delta \mathrm{S}^{0}\right)$ are calculated from the slope and the intercept of the linear plot of $\ln$ $\mathrm{K}_{c}$ vs. 1/T. The calculated values are summarized in Table 6 .

Table 6: Thermodynamic parameters for OPA and IPA sorption.

\begin{tabular}{|c|c|c|c|}
\hline Analyte & $\Delta \mathbf{S}^{\mathbf{0}} / \mathbf{J} \mathbf{~ m o l}^{\mathbf{- 1}} \mathbf{K}^{-\mathbf{1}}$ & $\Delta \mathbf{H}^{\mathbf{0}} / \mathbf{k J} \mathbf{~ m o l}^{-\mathbf{1}}$ & $\Delta \mathbf{G}^{\mathbf{0}} / \mathbf{k J} \mathbf{~ m o l}^{-\mathbf{1}}$ \\
\hline \multirow{3}{*}{ OPA } & \multirow{2}{*}{7.1} & -15.2 & $-17.3 / 303 \mathrm{~K}$ \\
& & & $-17.4 / 313 \mathrm{~K}$ \\
& & & $-17.5 / 323 \mathrm{~K}$ \\
\hline \multirow{2}{*}{ IPA } & 249.5 & 62.2 & $-13.4 / 303 \mathrm{~K}$ \\
& & & $-15.9 / 313 \mathrm{~K}$ \\
& & & $-18.4 / 323 \mathrm{~K}$ \\
\hline
\end{tabular}

The negative values of $\Delta G^{\circ}$ at all temperatures studied are due to the fact that the sorption process is spontaneous. The negative value of $\Delta H^{\circ}$ for OPA sorption suggests the exothermic nature of the sorption but it was endothermic for IPA sorption. The positive value of $\Delta S^{\circ}$ suggests increased randomness at the solid/solution interface during the sorption of OPA and IPA onto the resin.

3.7 Regeneration of the resin

Regeneration experiments were carried out as explained before [25] Evaluation of OPA or IPA loaded-resin regeneration with a different solution ( $\mathrm{NaOH}$ and $\mathrm{HCl}$ for OPA and $\mathrm{NaOH}, \mathrm{HCl}, \mathrm{NaCl}$ for IPA) was performed. 
Regeneration efficiency (RE, \%) was calculated using the Eqn (14) and the obtained results were summarized in Table 7.

$$
\mathrm{RE}(\%)=\frac{\text { Amount of eluated sorbate }}{\text { Amount of loaded sorbate }} \times 100
$$

Table 7: Percentage recovery of OPA and IPA by different regeneration solution.

\begin{tabular}{|c|c|c|}
\hline \multirow{2}{*}{ Regenerated by } & \multicolumn{2}{|c|}{ Regeneration (\%) } \\
\cline { 2 - 3 } & OPA & IPA \\
\hline $1.0 \mathrm{M} \mathrm{NaOH}$ & 39 & 15 \\
\hline $2.0 \mathrm{M} \mathrm{NaOH}$ & 49 & 25 \\
\hline $1.0 \mathrm{M} \mathrm{HCl}$ & 95 & 38 \\
\hline $2.0 \mathrm{M} \mathrm{HCl}$ & 100 & 44 \\
\hline $1.0 \mathrm{M} \mathrm{NaCl}$ & N.E & 97 \\
\hline $2.0 \mathrm{M} \mathrm{NaCl}$ & N.E & 100 \\
\hline
\end{tabular}

N.E. Not examined

As can be seen from Table 7, the OPA-loaded resin can be completely regenerated by $2.0 \mathrm{M} \mathrm{HCl}$. The regeneration of IPA-loaded resin is possible with $2.0 \mathrm{M} \mathrm{NaCl}$ resin. The difference in regeneration performance with the same solution is due to different physical and chemical properties of OPA and IPA.

\section{CONCLUSIONS}

The main goal of this study was the evaluation of the performance ion exchange resin on the removal of phthalic acid isomers from the water. The ion exchange reaction process was fast and equilibrium was established in $60 \mathrm{~min}$. The percentage removal of OPA and IPA is $\mathrm{pH}$ dependent and it was decreased with a decrease in initial $\mathrm{pH}$ of the solution. The equilibrium sorption of OPA and IPA onto Finex AS510GC resin followed the Langmuir sorption isotherm with a maximum theoretical sorption capacity of $397.8 \mathrm{mg} / \mathrm{g}$ for OPA and $331.3 \mathrm{mg} / \mathrm{g}$ is IPA. The sorption of OPA and IPA on resin was found to be mainly based on ion-exchange interactions, and these were confirmed by the Dubinin-Radushkevich model. Ion exchange kinetics of isomers fitted well with the pseudo-first-order model. The experimental data fitted to the HPDM and SPM models and obtained results demonstrated that the rate determining step is film diffusion for both solute and according to the SPM model, chemical reaction was the rate-limiting step for OPA sorption and reacted layer was for IPA sorption.

Temperature variations were used to evaluate enthalpy $\Delta H$, entropy $\Delta S$, and Gibbs free energy $\Delta G$ values. The negative value of $\Delta G$ showed the spontaneous nature of the ion exchange reaction. The OPA-loaded resin can be regenerated with $2.0 \mathrm{M} \mathrm{HCl}$ and $2.0 \mathrm{M} \mathrm{NaCl}$ solution can be used for stripping IPA-loaded resin.

\section{ACKNOWLEDGMENTS}

This study was supported by The Scientific and Technological Research Council of Turkey (TUBITAK-Program code: 2209). We would like to acknowledge Finex Company for providing us the resin sample.

\section{REFERENCES}

1. K. M. Gani and A. A. Kazmi, Crit. Rev. Environ. Sci. Technol. 46, 1402 (2016).

2. M. Julinova and R. Slavik, J. Environ. Manage. 94, 13 (2012).

3. W. Zhang, Z. Xu, B. Pan, L. Lv, Q. Zhang, Q. Zhang, W. Du, B. Pan, and Q. Zhang, J. Colloid Interface Sci. 311, 382 (2007).

4. M. M. Abdel daiem, J. Rivera-Utrilla, R. Ocampo-Pérez, J. D. MéndezDíaz, and M. Sánchez-Polo, J. Environ. Manage. 109, 164 (2012).

5. M. Matsumoto, M. Hirata-Koizumi, and M. Ema, Regul. Toxicol. Pharmacol. 50, 37 (2008).

6. Y. Wang, G. Zhang, and L. Wang, J. Agric. Food Chem. 63, 75 (2015).

7. A. Gómez-Hens and M. P. Aguilar-Caballos, TrAC - Trends Anal. Chem. 22, 847 (2003)
8. D. W. Gao and Z. D. Wen, Sci. Total Environ. 541, 986 (2016).

9. N. A. Khan, B. K. Jung, Z. Hasan, and S. H. Jhung, J. Hazard. Mater. 282, 194 (2015).

10. E. Parlak and Ö. Arar, J. Dispers. Sci. Technol. 39, 1403 (2018).

11. C.-M. Park and R. J. Sheehan, in Kirk-Othmer Encycl. Chem. Technol. (2000), pp. 17-18.

12. C. Kaya, A. Șahbaz, Ö. Arar, Ü. Yüksel, and M. Yüksel, Desalin. Water Treat. 55, (2015)

13. M. A. Güngör, Ö. Özalp, and Ö. Arar, Desalin. Water Treat. 88, 279 (2017).

14. B. Alyüz and S. Veli, J. Hazard. Mater. 167, 482 (2009).

15. P. Liu, Y. Li, Y. Xu, Y. Qing, and C. Han, J. Chil. Chem. Soc. 63, 3819 (2018).

16. A. Erdem Yayayürük and O. Yayayürük, J. Chem. Technol. Biotechnol. 92, 1891 (2017)

17. T. Mahmood, M. Aslam, A. Naeem, T. Siddique, and S. U. Din, J. Chil. Chem. Soc. 63, 3855 (2018).

18. A. Altinisik, Y. Seki, S. Ertas, E. Akar, E. Bozac1, and Y. Seki, Fibers Polym. 16, 370 (2015).

19. Y. S. Ho and G. McKay, Process Biochem. 34, 451 (1999).

20. Y. S. Ho and G. McKay, Chem. Eng. J. 70, 115 (1998).

21. G. Schmuckler and S. Goldstein, in Ion Exch. Solvent Extr. A Ser. Adv. Vol. 7, edited by J. A. Marinsky and Y. Marcus, First (Dekker, New York, 1977), pp. 1-28.

22. M. Caetano, C. Valderrama, A. Farran, and J. L. Cortina, J. Colloid Interface Sci. (2009)

23. D. V. Morales, B. L. Rivas, and M. González, J. Chil. Chem. Soc. 61, 3295 (2016).

24. B. Aşçı, E. Kövenç, Ö. Arar, and M. Arda, Glob. NEST J. 20, 368 (2018).

25. Ö. Arar, Anadolu Univ. J. Sci. Technol. Appl. Sci. Eng. 17, 530 (2016) 